\title{
Presepsin and procalcitonin as predictors of sepsis based on the new Sepsis-3 definitions in obstructive acute pyelonephritis
}

Mitsuhiro Tambo*, Satoru Taguchi, Yu Nakamura, Takatsugu Okegawa and Hiroshi Fukuhara

\begin{abstract}
Background: Acute pyelonephritis (APN) with obstructive uropathy often causes sepsis. Recently, sepsis was redefined using the sequential organ failure assessment (SOFA) score, based on the new Sepsis-3 criteria. We investigated predictors for sepsis using this new definition in patients with obstructive APN associated with upper urinary tract calculi.

Methods: We retrospectively evaluated patients who were admitted to our hospital for treatment of obstructive APN associated with upper urinary tract calculi. Blood and urine samples were collected before treatment of obstructive APN. Treatment included adequate antimicrobial therapy and emergency drainage to decompress the renal collecting system. We diagnosed sepsis using the new Sepsis-3 definition. We assessed predictors for sepsis by multivariate logistic regression analysis.

Results: Sixty-one patients were included in this study. Overall, all patients underwent emergency drainage, and 11 (18.0\%) patients showed sepsis. There were no significant differences in performance status or comorbidities between sepsis and non-sepsis groups. Platelet count and serum albumin level were significantly lower in the sepsis group than in the non-sepsis group ( $p=0.001$ and $p=0.016$, respectively). Procalcitonin (PCT) and presepsin (PSEP) levels were significantly higher in the sepsis group than in the non-sepsis group $(p<0.001$ and $p<0.001$, respectively). Multivariate analysis showed that PCT elevation $(\mathrm{OR}=13.12, p=0.024)$ and PSEP elevation $(\mathrm{OR}=13.13$, $p=0.044$ ) were independent predictors for sepsis.
\end{abstract}

Conclusions: Elevation of PCT and PSEP levels before treatment might predict the development of sepsis in patients with obstructive APN.

Keywords: Acute pyelonephritis, Upper urinary tract calculi, Sepsis, Procalcitonin, Presepsin

\section{Background}

Sepsis is a major cause of morbidity and mortality among hospitalized patients, and its reported incidence is increasing [1]. Until recently, sepsis was defined as the presence of two or more positive systemic inflammatory

\footnotetext{
*Correspondence: tanbodes@ks.kyorin-u.ac.jp

Department of Urology, Kyorin University School of Medicine, Shikawa 6-20-2, Mitaka, Tokyo 181-8611, Japan
}

response syndrome (SIRS) criteria and confirmed infection [2]. However, SIRS criteria are limited in that they exhibit inadequate specificity and sensitivity for dysregulated, life-threatening responses [3]. In 2015, sepsis was redefined (Sepsis-3 criteria) to emphasize the role of organ dysfunction, using the sequential organ failure assessment (SOFA) [4]. 
Urosepsis is commonly caused by obstructive disease of the urinary tract, such as urinary stones, stenosis, and tumor, and affects $20-30 \%$ of all septic patients [5]. A Japanese multicenter survey revealed that the rate of urosepsis based on SIRS criteria was $35.4 \%$ in patients with obstructive acute pyelonephritis (APN) secondary to urolithiasis [6]. A recent retrospective study showed that SOFA was more useful than SIRS for prediction of mortality in patients with APN associated with upper urinary tract calculi [7]. Most previous studies of sepsis have discussed biomarkers for sepsis and septic shock [8]; to the best of our knowledge, there have been no reports regarding markers for sepsis, based on the new definitions, in patients with obstructive APN. Thus, we investigated the predictors for sepsis based on the new definitions in patients with obstructive APN associated with upper urinary tract calculi.

\section{Methods}

This retrospective study was based on a medical chart review of patients who were admitted to our institution for the treatment of obstructive APN with upper urinary tract calculi between September 2015 and February 2018. The definition of APN and the regimen of antimicrobial treatment that we used were described in our previous report [8]. Patients who developed APN associated with surgical intervention were excluded from the final cohort to eliminate a potential bias. Prior to the initiation of treatment, blood samples were collected for biochemical and biomarker measurements, including procalcitonin (PCT) and presepsin (PSEP). Patients who had severe chronic kidney disease (estimated glomerular filtration rate $[\mathrm{eGFR}]<30 \mathrm{~mL} / \mathrm{min} / 1.73 \mathrm{~m}^{2}$ ) at baseline were also excluded from the final cohort to minimize the impact of kidney function on PCT and/or PSEP values. The severity of acute kidney injury (AKI) was graded according to the AKI network (AKIN) criteria [9]. Midstream urine and blood culture analyses with antimicrobial susceptibility tests were carried out for all patients. When a responsible bacterium showed resistance to the initial empirical treatment, the antibacterial agent was changed into another one to which the bacterium was susceptible. For the purpose of initial emergency drainage of the renal collecting system, retrograde ureteral stenting was generally carried out for most cases, whereas percutaneous nephrostomy was carried out for those who failed initial treatment or supposedly unfit cases for ureteral stenting (e.g. those who had histories of urinary tract abnormalities or severe hydronephrosis). Detailed procedures for retrograde ureteral stenting and percutaneous nephrostomy were described in our previous report [8].

Sepsis was defined based on the Sepsis-3 criteria. Briefly, patients with suspected infection were evaluated using the quick SOFA (qSOFA) (two or more of the following: respiratory rate $\geq 22 / \mathrm{min}$, altered mental state, and systolic blood pressure $\leq 100 \mathrm{mmHg}$ ). Patients with positive for qSOFA and $\geq 2$ SOFA score points were diagnosed with sepsis [4]. Performance status was classified in accordance with the Eastern Cooprative Oncology Group performance status classification. Cardiovascular or neurologic diseases and immunocompromised status were described in our previous report [8]. Risk stratification of comorbidity was classified using the Charlson Comorbidity Index [10]. The severity of hydronephrosis was categorized as low-grade and high-grade, as reported previously [8]. This study was approved by the Faculty of Medicine Research Ethics Committee, Kyorin University (approval No. H30196). The review board waived the requirement for consent due to the retrospective nature of the study.

\section{Statistical analysis}

The variables were compared among groups using the Mann-Whitney U-test and Kruskal-Wallis test. The independence of categorical data was estimated by the chisquared test or Fisher's exact test. Continuous variables (age, serum creatinine level, leukocyte counts, C-reactive protein (CRP) level, platelet count, serum albumin level, PCT level, and PSEP level) were used to divide the patients into two groups by receiver operating characteristic curve analysis. Independent predictors of sepsis were determined using logistic regression analysis. Differences with $p<0.05$ were considered to be statistically significant. Statistical analyses were conducted using SPSS software (version 18.0, IBM Corp., Armonk, NY, USA).

\section{Results}

This study included 61 patients. Median patient age was 64 years, 24 patients were male and 37 patients were female. In total, five patients $(8.2 \%)$ exhibited poor performance status (2-4). Of the 61 patients, there were 16, eight, six, three, and two with diabetes mellitus, cardiovascular diseases, neurologic diseases, immunocompromised status, and urinary tract abnormalities, respectively. Median serum creatinine was $1.22 \mathrm{mg} / \mathrm{dL}$. Overall, 41 patients $(67.2 \%)$ showed a large shift in leukocyte count $(<4000$ or $>12,000 / \mu \mathrm{L})$. Twenty and 19 patients exhibited reduced platelet count $(<150,000 / \mu \mathrm{L})$ and reduced serum albumin level $(<3.1 \mathrm{~g} / \mathrm{dL})$, respectively. Median PCT and PSEP levels were $1.49 \mathrm{ng} / \mathrm{mL}$ and $445 \mathrm{pg} / \mathrm{mL}$, respectively. PCT and PSEP levels increased significantly with the severity of AKI (Table 1). In total, 54 (88.5\%) and 22 patients (36.1\%) showed bacterial growth in midstream urine culture and blood culture, respectively.

Most stones were located in the ureter (90.2\%). The median longest and shortest diameters of stones were $8.0 \mathrm{~mm}$ and $5.0 \mathrm{~mm}$, respectively. Overall, 22 patients (36.1\%) had high-grade hydronephrosis. Fifty-six (91.8\%) 
Table 1 PCT and PSEP stratified by AKI grade according to the AKIN criteria

\begin{tabular}{llllll}
\hline Variables & AKl grade & & & & P-value \\
\cline { 2 - 5 } & $\begin{array}{l}\text { Grade 0 } \\
(n=20)\end{array}$ & $\begin{array}{l}\text { Grade 1 } \\
(n=34)\end{array}$ & $\begin{array}{l}\text { Grade 2 } \\
(n=3)\end{array}$ & $\begin{array}{l}\text { Grade 3 } \\
(n=4)\end{array}$ & \\
\hline $\begin{array}{l}\text { PCT, median } \\
(\mathrm{ng} / \mathrm{mL})\end{array}$ & 0.40 & 1.89 & 84.45 & 113.46 & 0.015 \\
$\begin{array}{l}\text { PSEP, median } \\
(\mathrm{pg} / \mathrm{mL})\end{array}$ & 335 & 528 & 835 & 740 & 0.001 \\
\hline
\end{tabular}

PCT Procalcitonin, PSEP Presepsin, AKI Acute kidney injury, AKIN Acute kidney injury network

and five patients (8.2\%) underwent indwelling ureteral stenting and nephrostomy, respectively, to achieve decompression of the collecting system. The median duration from initial treatment to decompression of the collecting system was 1.0 days.

In total, 11 patients (18.0\%) were positive for sepsis, using the Sepsis-3 criteria (Fig. 1). One patient (1.6\%) died of the infection. Age did not significantly differ between sepsis and non-sepsis groups $(p=0.209)$. Performance status and underlying diseases did not significantly differ between sepsis and non-sepsis groups. With respect to laboratory data before treatment, platelet count and serum albumin level were significantly lower in the sepsis group than in the non-sepsis group $(p=0.001$ and $p=0.016$, respectively). However, inflammatory markers (leukocyte count and CRP level) and serum creatinine did not significantly differ between sepsis and non-sepsis groups ( $p=$ 0.073, $p=0.586$, and $p=0.058$, respectively). PCT and PSEP levels were significantly higher in the sepsis group than in the non-sepsis group $(p<0.001$ and $p<0.001$, respectively). There were no significant differences in stone characteristics between the sepsis and non-sepsis groups (Table 2).

Multivariate logistic regression analysis showed that elevated PCT and PSEP levels were predictors for sepsis in patients who had obstructive APN associated with upper urinary tract calculi (Table 3 ).

\section{Discussion}

The present study showed that elevated PCT and PSEP levels before treatment might be independent predictors for sepsis, based on the Sepsis-3 criteria, in patients with obstructive APN. Obstructive APN can be lethal, and a

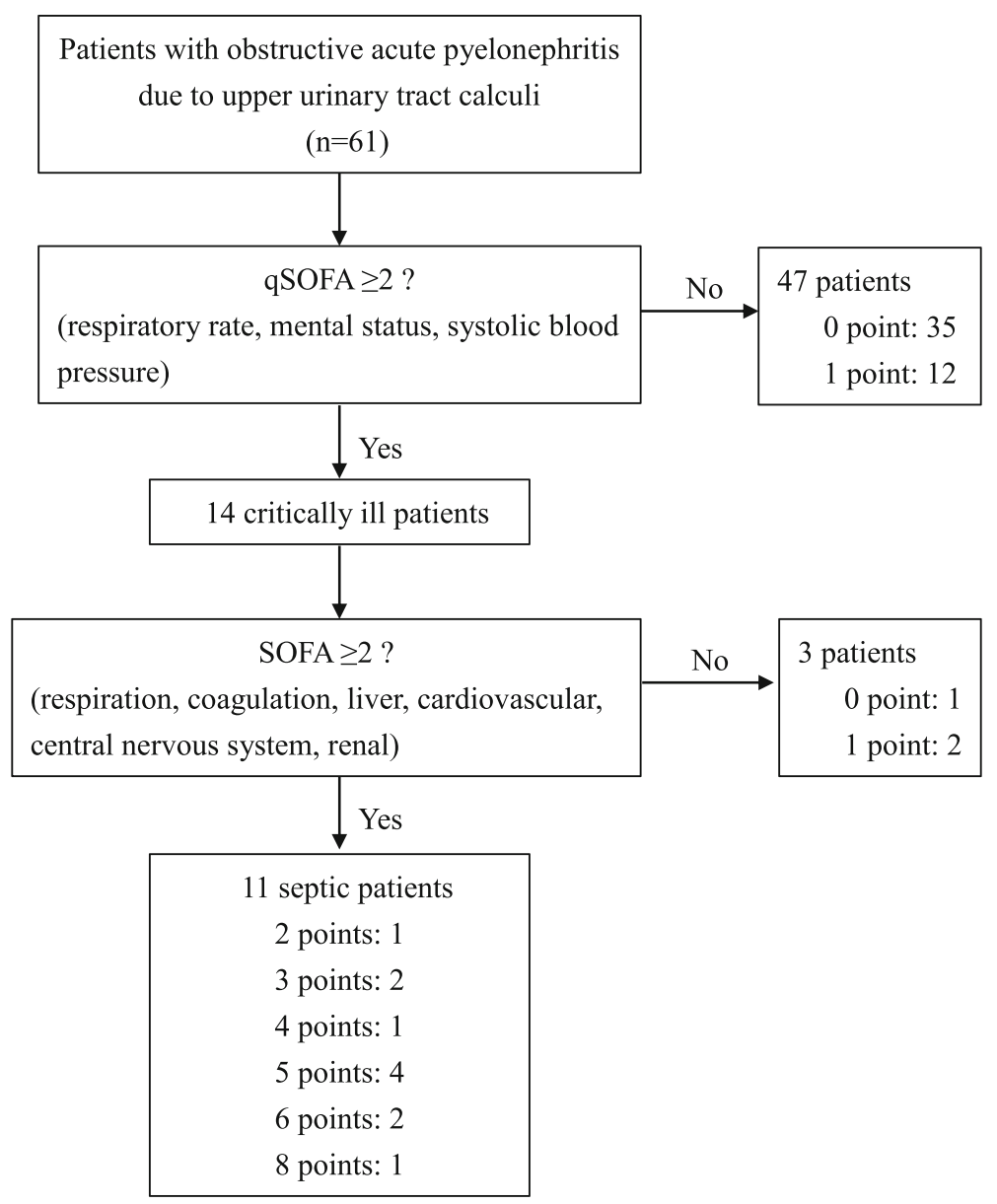

Fig. 1 Flow chart representing the diagnostic process of sepsis according to the Sepsis-3 criteria 
Table 2 Characteristics of patients with and without sepsis

\begin{tabular}{|c|c|c|c|c|c|c|c|}
\hline \multirow[t]{2}{*}{ Variables } & & & \multicolumn{2}{|l|}{ Sepsis group } & \multicolumn{2}{|l|}{ Non-sepsis group } & \multirow[t]{2}{*}{$P$-value } \\
\hline & & & $n$ & $\%$ & $n$ & $\%$ & \\
\hline Patients & & & 11 & & 50 & & \\
\hline Age (yr) & & Median [IQR] & $73[55-77]$ & & $61[52-76]$ & & 0.209 \\
\hline \multirow[t]{2}{*}{ Gender } & & Male & 3 & 27.3 & 21 & 42.0 & \\
\hline & & Female & 8 & 72.7 & 29 & 58.0 & 0.365 \\
\hline \multirow{2}{*}{\multicolumn{2}{|c|}{ Performance status }} & 0,1 & 9 & 81.8 & 47 & 94.0 & \\
\hline & & 2,3 & 2 & 18.2 & 3 & 6.0 & 0.182 \\
\hline \multirow{2}{*}{\multicolumn{2}{|c|}{ Diabetes mellitus }} & Negative & 8 & 72.7 & 37 & 74.0 & \\
\hline & & Positive & 3 & 27.3 & 13 & 26.0 & 0.931 \\
\hline \multirow{2}{*}{\multicolumn{2}{|c|}{ Cardiovascular or neurologic disease }} & Negative & 7 & 63.6 & 42 & 84.0 & \\
\hline & & Positive & 4 & 36.4 & 8 & 16.0 & 0.124 \\
\hline \multirow{2}{*}{\multicolumn{2}{|c|}{ Immunocompromised status }} & Negative & 10 & 90.9 & 48 & 96.0 & \\
\hline & & Positive & 1 & 9.1 & 2 & 4.0 & 0.480 \\
\hline \multirow[t]{2}{*}{$\mathrm{CCl}$ scores } & & $0-2$ & 8 & 72.7 & 47 & 94.0 & \\
\hline & & $\geq 3$ & 3 & 27.3 & 3 & 6.0 & 0.066 \\
\hline Serum creatinine $(\mathrm{mg} / \mathrm{dL})$ & & Median [IQR] & $1.50[1.22-2.14]$ & & $1.17[0.78-1.70]$ & & 0.058 \\
\hline Leukocyte counts $\left(\times 10^{3} / \mathrm{\mu L}\right)$ & & Median [IQR] & $18.3[10.0-22.3]$ & & $12.8[10.1-15.5]$ & & 0.073 \\
\hline C-reactive protein (mg/dL) & & Median [IQR] & $14.17[4.84-24.51]$ & & $10.72[6.66-16.34]$ & & 0.586 \\
\hline Platelet counts $\left(\times 10^{4} / \mu \mathrm{L}\right)$ & & Median [IQR] & $10.1[6.1-14.8]$ & & $19.2[15.5-26.9]$ & & 0.001 \\
\hline Serum albumin (g/dL) & & Median [IQR] & $3.0[2.6-3.5]$ & & $3.6[3.2-4.0]$ & & 0.016 \\
\hline $\mathrm{PCT}(\mathrm{ng} / \mathrm{mL})$ & & Median [IQR] & $31.57[1.83-134.40]$ & & $0.54[0.14-4.86]$ & & $<0.001$ \\
\hline PSEP $(p g / m L)$ & & Median [IQR] & 1080 [696-1550] & & 387 [313-558] & & $<0.001$ \\
\hline \multirow{2}{*}{\multicolumn{2}{|c|}{ Midstream urine culture }} & Negative & 0 & 0.0 & 7 & 14.0 & \\
\hline & & Positive & 11 & 100.0 & 43 & 86.0 & 0.187 \\
\hline \multirow{2}{*}{\multicolumn{2}{|c|}{ Blood culture }} & Negative & 1 & 9.1 & 38 & 76.0 & \\
\hline & & Positive & 10 & 90.9 & 12 & 24.0 & $<0.001$ \\
\hline \multirow{2}{*}{\multicolumn{2}{|c|}{ Hydronephrosis }} & Low-grade & 7 & 63.6 & 32 & 64.0 & \\
\hline & & High-grade & 4 & 36.4 & 18 & 36.0 & 0.982 \\
\hline \multirow{2}{*}{\multicolumn{2}{|c|}{ Laterality of stone }} & Right & 5 & 45.5 & 25 & 50.0 & \\
\hline & & Left & 6 & 54.5 & 25 & 50.0 & 0.785 \\
\hline \multirow[t]{4}{*}{ Position of stone } & & Renal pelvis or PUJ & 2 & 18.2 & 4 & 8.0 & \\
\hline & & Upper ureter & 6 & 54.5 & 29 & 58.0 & \\
\hline & & Mid ureter & 1 & 9.1 & 8 & 16.0 & \\
\hline & & Lower ureter & 2 & 18.2 & 9 & 18.0 & 0.738 \\
\hline \multirow[t]{2}{*}{ Size of stone $(\mathrm{mm})$} & Longest diameter & Median [IQR] & $7.0[5.0-12.0]$ & & $8.0[6.0-10.0]$ & & 0.806 \\
\hline & Shortest diameter & Median [IQR] & $4.0[3.0-8.0]$ & & $5.0[4.0-7.0]$ & & 0.842 \\
\hline \multirow[t]{2}{*}{ Drainage } & & Ureteral stent & 10 & 90.9 & 46 & 92.0 & \\
\hline & & Nephrostomy & 1 & 9.1 & 4 & 8.0 & 0.905 \\
\hline
\end{tabular}

CCI Charlson Comorbidity Index, PCT Procalcitonin, PSEP Presepsin, PUJ Pelvic ureteral junction

recent survey revealed a mortality rate of $2.3 \%$ [6]. Based on the new definition, a diagnosis of sepsis is associated [11]. Thus, patients who have obstructive APN and who have elevated PCT and PSEP levels before treatment might exhibit a risk of mortality. However, in adult patients with uncomplicated APN, Cleassens et al. reported that the performance of PSEP level for prediction of positive blood culture (area under the receiver operating characteristic curve $[\mathrm{AUC}]=0.63$ ) was similar to that of CRP level (AUC $=0.64)$ and less accurate than that of PCT level (AUC $=0.78, p<0.001)$ [12]. The limitations of the study by Cleassens et al. included a low rate of bacterial 
Table 3 Odds ratio for sepsis in relation to various factors by logistic regression analysis

\begin{tabular}{|c|c|c|c|c|c|c|c|}
\hline \multirow[t]{2}{*}{ Variables } & & \multicolumn{3}{|c|}{ Univariate } & \multicolumn{3}{|c|}{ Multivariate } \\
\hline & & $\overline{\mathrm{OR}}$ & $95 \% \mathrm{Cl}$ & $\overline{p \text {-value }}$ & $\overline{\mathrm{OR}}$ & $95 \% \mathrm{Cl}$ & $\overline{p \text {-value }}$ \\
\hline \multirow[t]{2}{*}{ Age (yr) } & $64 \geq$ & Ref & & & & & \\
\hline & $64<$ & 3.13 & $(0.74-13.20)$ & 0.120 & & & \\
\hline \multirow[t]{2}{*}{ Gender } & Male & Ref & & & & & \\
\hline & Female & 1.93 & $(0.46-8.16)$ & 0.370 & & & \\
\hline \multirow[t]{2}{*}{ Performance status } & 0,1 & Ref & & & & & \\
\hline & 2,3 & 3.48 & $(0.51-23.89)$ & 0.204 & & & \\
\hline \multirow[t]{2}{*}{ Diabetes mellitus } & Negative & Ref & & & & & \\
\hline & Positive & 1.07 & $(0.25-4.64)$ & 0.930 & & & \\
\hline \multirow[t]{2}{*}{ Cardiovascular or neurologic disease } & Negative & Ref & & & & & \\
\hline & Positive & 3.00 & $(0.71-12.69)$ & 0.136 & & & \\
\hline \multirow[t]{2}{*}{ Immunocompromised status } & Negative & Ref & & & & & \\
\hline & Positive & 2.40 & $(0.20-29.10)$ & 0.492 & & & \\
\hline \multirow[t]{2}{*}{ History of urinary tract abnormalities } & Negative & Ref & & & & & \\
\hline & Positive & 1.21 & $(0.15-9.82)$ & 0.860 & & & \\
\hline \multirow[t]{2}{*}{$\mathrm{CCl}$ scores } & $0-2$ & Ref & & & & & \\
\hline & $\geq 3$ & 5.87 & $(1.00-34.39)$ & 0.050 & & & \\
\hline \multirow[t]{2}{*}{ Serum creatinine $(\mathrm{mg} / \mathrm{dL})$} & $1.26 \geq$ & Ref & & & & & \\
\hline & $1.26<$ & 3.39 & $(0.80-14.32)$ & 0.096 & & & \\
\hline \multirow[t]{2}{*}{ Leukocyte counts $\left(\times 10^{3} / \mu \mathrm{L}\right)$} & $13.1 \geq$ & Ref & & & & & \\
\hline & $13.1<$ & 3.13 & $(0.74-13.20)$ & 0.120 & & & \\
\hline \multirow[t]{2}{*}{ C-reactive protein (mg/dL) } & $10.83 \geq$ & Ref & & & & & \\
\hline & $10.83<$ & 1.20 & $(0.32-4.45)$ & 0.785 & & & \\
\hline \multirow[t]{2}{*}{ Platelet counts $\left(\times 10^{4} / \mu \mathrm{L}\right)$} & $15.0 \leq$ & Ref & & & Ref & & \\
\hline & $15.0>$ & 15.95 & $(3.00-84.92)$ & 0.001 & 3.23 & $(0.39-26.64)$ & 0.276 \\
\hline \multirow[t]{2}{*}{ Serum albumin (g/dL) } & $3.1 \leq$ & Ref & & & Ref & & \\
\hline & $3.1>$ & 5.54 & $(1.38-22.24)$ & 0.016 & 1.21 & $(0.15-9.82)$ & 0.860 \\
\hline \multirow[t]{2}{*}{ PCT (ng/mL) } & $23.55 \geq$ & Ref & & & Ref & & \\
\hline & $23.55<$ & 30.67 & $(5.75-163.67)$ & $<0.001$ & 13.12 & $(1.41-122.03)$ & 0.024 \\
\hline \multirow[t]{2}{*}{ PSEP (pg/mL) } & $515 \geq$ & Ref & & & Ref & & \\
\hline & $515<$ & 23.33 & $(2.73-198.87)$ & 0.004 & 13.13 & $(1.07-161.45)$ & 0.044 \\
\hline
\end{tabular}

CCI Charlson Comorbidity Index, PCT Procalcitonin, PSEP Presepsin, OR Odds ratio, Cl Confidence interval

detection in blood culture of sepsis patients, and low rate of sepsis in patients with uncomplicated APN.

A recent meta-analysis showed that PCT and PSEP levels had moderate diagnostic value for sepsis [13]. However, most previous studies reported that patients had SIRS and/or severe sepsis/septic shock. In addition, in a clinical study of sepsis based on the new definitions, multivariate analysis showed that patients who were admitted to the intensive care unit with high PSEP and PCT levels had significantly higher risk of sepsis, compared with that of patients with low PSEP and PCT levels [14]. The limitations of that study included the use of SIRS criteria for initial screening.
PCT is a prohormone of calcitonin; under normal conditions, it is only produced in C-cells of the thyroid gland. During infection, PCT can be produced by several cell types and many organs in response to proinflammatory cytokines (e.g., tumor necrosis factor- $\alpha$ and interleukin-6). Because it shows an early increase during infection, PCT is a useful biomarker for infection [15]. PSEP is the soluble form of CD14, a membranebased receptor that is expressed by macrophages and monocytes. PSEP is a complex product of CD14 cleavage that is released into the general circulation by proteolysis and exocytosis, which occur following bacterial antigen binding. PSEP levels are presumed to increase during early stages of bacterial infections, and may depend on 
the intensity of innate immune induction [16]. In an animal model of sepsis, PSEP in the blood was detected within $2 \mathrm{~h}$ and peaked after $3 \mathrm{~h}$, while PCT was elevated within $3-6 \mathrm{~h}$ and peaked at 6-8 $\mathrm{h}$ [17]. In contrast, elevated CRP levels have been found within $6-8 \mathrm{~h}$ of infection and peak after 36-50 h [18].

There were several limitations in this study. First, patients with severe chronic kidney disease (GFR $<30 \mathrm{~mL} /$ $\min / 1.73 \mathrm{~m}^{2}$ ) were excluded from analysis. PSEP levels inversely correlate with GFR, and PSEP levels in patients with GFR $<30 \mathrm{~mL} / \mathrm{min} / 1.73 \mathrm{~m}^{2}$ were reportedly significantly higher than those in patients with GFR $\geq 30 \mathrm{~mL} /$ $\min / 1.73 \mathrm{~m}^{2}$ [19]. The evaluation of PSEP levels in patients with chronic kidney disease thus requires special considerations, such that the present results may not be generalizable to those patients. In the present study, three patients with GFR $<30 \mathrm{~mL} / \mathrm{min} / 1.73 \mathrm{~m}^{2}$ demonstrated PSEP levels of $1150 \mathrm{pg} / \mathrm{mL}, 889 \mathrm{pg} / \mathrm{mL}$, and $3620 \mathrm{pg} / \mathrm{mL}$, respectively; all were negative for sepsis. Second, levels of PCT and PSEP could be influenced by acute kidney injury (AKI). Recently, a retrospective study in patients with AKI showed that different thresholds of PSEP and PCT levels might be useful markers of bacterial infections [20]. Another study demonstrated that the accuracy of sepsis diagnosis based on PCT level was significantly higher than that based on PSEP level in patients with severe AKI [21]. However, the values for cutoff levels, depending on renal function, remain controversial. Finally, our results were limited to a small number of enrolled patients and were retrospectively collected. Further studies should include larger prospective cohorts.

\section{Conclusions}

Elevated PCT and PSEP levels before treatment might predict the development of sepsis in patients with obstructive APN.

\section{Abbreviations}

AKI: Acute kidney injury; AKIN: Acute kidney injury network; APN: Acute pyelonephritis; CRP: C-reactive protein; PCT: Procalcitonin; PSEP: Presepsin; qSOFA: quick SOFA; SIRS: Systemic inflammatory response syndrome; SOFA: Sequential organ failure assessment

\section{Acknowledgments}

The authors thank Ryan Chastain-Gross, Ph.D., from Edanz Group (www.edanzediting.com/ac) for editing a draft of this manuscript.

\section{Authors' contributions}

MT performed project development, data collection, data analysis, and manuscript writing. ST contributed to data collection, data analysis, and manuscript editing. YN contributed to data collection and data analysis. TO and HF performed project development and manuscript editing. All authors read and approved the final manuscript.

\section{Funding}

The authors have no financial support and funding for carrying out this study.

\section{Availability of data and materials}

The datasets used and/or analysed during the current study are available from the corresponding author on reasonable request.

\section{Ethics approval and consent to participate}

This study was approved by the Faculty of Medicine Research Ethics Committee, Kyorin University (approval No. H30-196). The review board waived the requirement for consent due to the retrospective nature of the study.

Consent for publication

Not applicable.

\section{Competing interests}

The authors declare that they have no competing interests.

Received: 1 September 2019 Accepted: 3 March 2020

Published online: 11 March 2020

\section{References}

1. Gaieski DF, Edwards JM, Kallan MJ, Carr BG. Benchmarking the incidence and mortality of severe sepsis in the unites states. Crit Care Med. 2013;41: 1167-74.

2. Levy MM, Fink MP, Marshall JC, Abraham E, Angus D, Cook D, et al. 2001 SCCM/ESICM/ACCP/ATS/SIS international sepsis definitions conference. Intensive Care Med. 2003;29:530-8.

3. Churpek MM, Zadravecz FJ, Winslow C, Howell MD, Edelson DP. Incidence and prognostic value of the systemic inflammatory response syndrome and organ dysfunctions in ward patients. Am J Respir Crit Care Med. 2015;192: 958-64.

4. Singer M, Deutschman CS, Seymour CW, Shankar-Hari M, Annane D, Bauer $M$, et al. The third international consensus definitions for sepsis and septic shock (Sepsis-3). JAMA. 2016;315:801-10.

5. Brun-Buisson C. The epidemiology of the systemic inflammatory response. Intensive Care Med. 2000;26(Suppl 1):64-74.

6. Hamasuna R, Takahashi S, Nagae H, Kubo T, Yamamoto S, Arakawa S, et al. Obstructive pyelonephritis as a result of urolithiasis in Japan: diagnosis, treatment and prognosis. Int J Urol. 2015;22:294-300.

7. Fukushima H, Kobayashi M, Kawano K, Morimoto S. Performance of quick sequential (sepsis related) and sequential (sepsis related) organ failure assessment to predict mortality in patients with acute pyelonephritis associated with upper urinary tract calculi. J Urol. 2018;199:1526-33.

8. Tambo M, Okegawa T, Shishido T, Higashihara E, Nutahara K. Predictors of septic shock in obstructive acute pyelonephritis. World J Urol. 2014;32:80311.

9. Mehta RL, Kellum JA, Shah SV, Molitoris BA, Ronco C, Warnock DG, et al. Acute kidney injury network: report of an initiative to improve outcomes in acute kidney injury. Crit Care. 2007;11:R31.

10. Frenkel WJ, Jongerius EJ, Mandjes-van Uitert MJ, van Munster BC, de Rooij SE. Validation of the Charlson comorbidity index in acutely hospitalized elderly adults: a prospective cohort study. J Am Geriatr Soc. 2014;62:342-6.

11. Seymour CW, Liu VX, Iwashyna TJ, Brunkhorst FM, Rea TD, Scherag A, et al. Assessment of clinical criteria for sepsis: for the third international consensus definitions for sepsis and septic shock (Sepsis-3). JAMA. 2016;315: 762-74.

12. Claessens YE, Trabattoni E, Grabar S, Quinquis L, Der Sahakian G, Anselmo $\mathrm{M}$, et al. Plasmatic presepsin (sCD14-ST) concentrations in acute pyelonephritis in adult patients. Clin Chim Acta. 2017:464:182-8.

13. Wu CC, Lan HM, Han ST, Chaou CH, Yeh CF, Liu SH, et al. Comparison of diagnostic accuracy in sepsis between presepsin, procalcitonin, and Creactive protein: a systematic review and meta-analysis. Ann Intensive Care. 2017;7:91.

14. Yamamoto T, Nishimura T, Kaga S, Uchida K, Tachibana Y, Esaki M, et al. Diagnostic accuracy of presepsin for sepsis by the new Sepsis-3 definitions. Am J Emerg Med. 2019;37(10):1936. https://doi.org/10.1016/j.ajem.2019.01. 025.

15. Wacker C, Prkno A, Brunkhorst FM, Schlattmann P. Procalcitonin as a diagnostic marker for sepsis: a systematic review and meta-analysis. Lancet Infect Dis. 2013;13:426-35. 
16. Chenevier-Gobeaux C, Borderie D, Weiss N, Mallet-Coste T, Claessens YE. Presepsin (sCD14-ST), an innate immune response marker in sepsis. Clin Chim Acta. 2015;450:97-103.

17. Maruna P, Nedelnikova K, Gürlich R. Physiology and genetics of procalcitonin. Physiol Res. 2000;49(Suppl.1):57-61.

18. Lelubre C, Anselin S, Zouaoui Boudjeltia K, Biston P, Piagnerelli M. Interpretation of C-reactive protein concentrations in critically ill patients. Biomed Res Int. 2013. https://doi.org/10.1155/2013/124021.

19. Nagata T, Yasuda $Y$, Ando M, Abe T, Katsuno T, Kato $S$, et al. Clinical impact of kidney function on presepsin levels. PLoS One. 2015;10:e0129159.

20. Takahashi G, Shibata S, Fukui Y, Okamura Y, Inoue Y. Diagnostic accuracy of procalcitonin and presepsin for infectious disease in patients with acute kidney injury. Diagn Microbiol Infect Dis. 2016;86:205-10.

21. Nakamura Y, Hoshino K, Kiyomi F, Kawano Y, Mizunuma M, Tanaka J, et al. Comparison of accuracy of presepsin and procalcitonin concentrations in diagnosing sepsis in patients with and without acute kidney injury. Clin Chim Acta. 2019:490:200-6.

\section{Publisher's Note}

Springer Nature remains neutral with regard to jurisdictional claims in published maps and institutional affiliations.

Ready to submit your research? Choose BMC and benefit from:

- fast, convenient online submission

- thorough peer review by experienced researchers in your field

- rapid publication on acceptance

- support for research data, including large and complex data types

- gold Open Access which fosters wider collaboration and increased citations

- maximum visibility for your research: over $100 \mathrm{M}$ website views per year

At BMC, research is always in progress.

Learn more biomedcentral.com/submissions 